\title{
LIX. Notices respecting new books
}

\section{A.G. Greenhill}

To cite this article: A.G. Greenhill (1889) LIX. Notices respecting new books, Philosophical Magazine Series 5, 27:169, 525-526, DOI: 10.1080/14786448908628392

To link to this article: http://dx.doi.org/10.1080/14786448908628392

册 Published online: 29 Apr 2009.

Submit your article to this journal $\pi$

Џll Article views: 3

Q View related articles ¿ 


\section{[ 525 ] \\ LIX. Notices respecting New Books.}

A Treatise on Hydrodynamics, with numerous Examples. Vol. II. By A. B. Basser, M.A. Cambridge: Deighton, Bell, and Co., 1888.

$\mathrm{W}^{\mathrm{E}}$ have not had long to wait for the completion of this important work, and now we possess a valuable treatise on Hydrodynamies carefully brought up to date. Considering the great advances made by the recent work of Lord Rayleigh, Poincaré, Hicks, J. J. Thomson, G. H. Darwin, and Love, the author must have devoted much time and trouble to the task of embodying their results and processes in a concise form in this second volume.

So many analytical difficulties of pure mathematics block the way to future progress, that the present work is necessarily only addressed to advanced mathematicians, conversant with Bessel, Elliptic, Spherical Harmonic, Spheroidal, and Toroidal Functions ; and incidentally in the course of the hydrodynamical investigations many elegant theorems in Pure Mathematics drop out, important enough to set up in his business a pure mathematician.

Chapter xii. of the present volume is a resume of the chief properties of these functions, required in chaps. xii. and xiv. on the properties of rectilinear and circular vortices, the latter embodying the most important researches of J. J. Thomson.

In chapter $x v$. the motion of a rotating liquid ellipsoid under the influence of its own attraction is discussed, from the points of view of Jacobi, Riemann, Dirichlet, Sir W. Thomson, Poincaré, and G. H. Darwin. The discussion of the stability of the motion is one of the most refined operations of modern analysis, and important in its bearing on the subject of the Figure of the Earth, and General Cosmogony, including the Genesis of the Moon, recently investigated by $\mathrm{Mr}$. Love, too recently, however, to be embodjed in the present volume.

Chapter xvii. treats of all the hitherto solved questions on Liquid Waves, and here analytical difficulties still restrict us to the consideration of waves of small displacement. This restriction is, however, a legitimate working hypothesis when we come to the grand Theory of the Tides, chapter xix., with which the names of Newton, but principally of Laplace are associated; and now recently undertaken afresh by Prof. G. H. Darwin.

The remainder of the volume is devoted to the investigation of the simple cases of liquid motion it is possible to discuss mathematically at present, when the disturbing effect due to a viscosity in the liquid in motion is taken into account. Some important experiments made recently by Prof. Osborne Reynolds have redirected attention to this important question, and shown the path for theoretical investigation.

We venture to defend again the expression "with numerous examples" appearing on the title-page, an expression which will call forth disapproval in certain quarters. These examples are carefully selected and verified; they afford a welcome recreation to

Phil. Mag. S. 5. Vol. 27. No. 169. June $1889 . \quad 2 \mathrm{~N}$ 
the enthusiastic student; and finally possess the great advantage of condensing into a few lines a mass of information, which otherwise would, in the continental fashion, have swelled this book to double its present dimensions.

The student of Hydrodynamics should be very grateful to the author, Mr. Basset, for an elegant treatise, which will place him abreast of the present state of development of the subject.

\section{A. G. Greenhill.}

\section{Intelligence and Miscellaneous Articles.}

ON THE PASSAGE OF ELECTRICITY THROUGH BAD CONDUCTORS. BY HUGO KOLLER.

THE author closes the imperfect dielectric to be investigated with a known resistance in the sircuit of a voltaic battery, and determines the fall of potential, which is found to be proportional to the strength of the current.

The transport of electricity through imperfect dielectries is seen to be different from that through true conductors in three points.

1. If a current of constant electromotive force traverses a condenser formed of an imperfect djelectric, its intensity diminishes with the time at first rapidly, and afterwards more slowly, approaching a definite limit along an asymptotic curve. With one and the same dielectric these changes in intensity take place the more rapidly the greater the tension in the condenser, and the smaller the quantity of dielectric between the electrodes.

2. The strength of the current increases more slowly than the electromotive force producing it.

3. The apparent specific resistance of dielectrics diminishes with their thickness.

This behaviour involves deviations from Ohm's law, of which the former is the more important, as the two latter may perhaps be partially if not altogether referred to the difference in the variation of intensity according to the dielectric tension and the thickness of the condenser.

Following an indication of Maxwell, the author endeavours to explain the decrease in the intensity of the current by referring the apparent currents which pass through a dielectric to three processes which are equivalent to currents.

1. To dielectric displacement.

2. To the formation of a residue.

3. To true conduction.

The influence of the first factor is soon exhausted, while the latter is independent of the time. The author considers the second, the influence of which becomes less with time, and finally disappears, as a transition between dielectric displacement and conduction. The quantities of electricity required for an electrical displacement remain in the form of electrical energy, while the quantities of electricity consumed in keeping up the conduction are transformed into heat. Imperfect conductors are not able to 